\title{
Identification of a DMBT1 Polymorphism Associated with Increased Breast Cancer Risk and Decreased Promoter Activity
}

Sandrine Tchatchou, ${ }^{1,2 * \dagger}$ Angela Riedel, ${ }^{3 \dagger}$ Stefan Lyer, ${ }^{4}$ Julia Schmutzhard, ${ }^{1,2}$ Olga Strobel-Freidekind ${ }^{4}$ Sabine Gronert-Sum, ${ }^{4}$ Carola Mietag, ${ }^{4}$ Mauro D'Amato ${ }^{5}$ Bettina Schlehe, ${ }^{2}$ Kari Hemminki, ${ }_{1}^{67}$ Christian Sutter, ${ }^{8}$

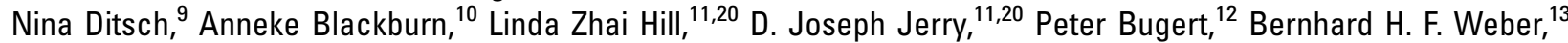
Dieter Niederacher, ${ }^{14}$ Norbert Arnold ${ }_{1}^{15}$ Raymonda Varon-Mateeva, ${ }^{16}$ Barbara Wappenschmidt, ${ }^{17}$ Rita K. Schmutzler, ${ }^{17}$ Christoph Engel, ${ }^{18}$ Alfons Meindl, ${ }^{19}$ Claus R. Bartram, ${ }^{8}$ Jan Mollenhauer, ${ }^{3,4 \ddagger}$ and Barbara Burwinkel, ${ }^{1,2 \ddagger}$

${ }^{1}$ Helmholtz-University Group Molecular Epidemiology, German Cancer Research Center (DKFZ), Heidelberg, Germany; ${ }^{2}$ Division Molecular Biology of Breast Cancer, Department of Gynecology and Obstetrics, University of Heidelberg, Heidelberg, Germany; ${ }^{3}$ Molecular Oncology, Medical Biotechnology Center, Institute for Medical Biology, University of Southern Denmark, Odense, Denmark; ${ }^{4}$ Division of Molecular Genome Analysis, German Cancer Research Center (DKFZ), Heidelberg, Germany; ${ }^{5}$ Department of Biosciences and Nutrition, Karolinska Institute, Stockholm, Sweden; ${ }^{6}$ Division of Molecular Genetic Epidemiology, German Cancer Research Center (DKFZ), Heidelberg, Germany; ${ }^{7}$ Department of Biosciences at Novum, Karolinska Institute, Huddinge, Sweden; ${ }^{8}$ Institute of Human Genetics, University of Heidelberg, Heidelberg, Germany; ${ }^{9}$ Department for Obstetrics and Gynaecology, Ludwig Maximilians Universität, Munich, Germany; ${ }^{10}$ John Curtin School of Medical Research, Australian National University, Canberra, Australian Capital Territory, Australia; ${ }^{11}$ Department of Veterinary and Animal Sciences, University of Massachusetts, Amherst, Massachusetts; ${ }^{12}$ Institute of Transfusion Medicine and Immunology, Red Cross Blood Service of Baden-WürttembergHessen, University of Heidelberg, Medical Faculty of Mannheim, Mannheim, Germany; ${ }^{13}$ Institute of Human Genetics, University of Regensburg, Regensburg, Germany; ${ }^{14}$ Division of Molecular Genetics, Department of Gynaecology and Obstetrics, Clinical Center University of Düsseldorf, Düsseldorf, Germany; ${ }^{15}$ Division of Oncology, Department of Gynaecology and Obstetrics, University Hospital Schleswig-Holstein, Kiel, Germany; ${ }^{16}$ Institut für Humangenetik, Charité-Universitätsmedizin Berlin, Berlin, Germany; ${ }^{17}$ Division of Molecular Gyneco-Oncology, Department of Gynaecology and Obstetrics, Center of Molecular Medicine Cologne (CMMC), University Hospital of Cologne, Cologne, Germany; ${ }^{18}$ Department of Medical Informatics, Statistics and Epidemiology, University of Leipzig, Leipzig, Germany; ${ }^{19}$ Division of Gynecology and Obstetrics, Klinikum rechts der Isar at the Technical University Munich, Munich, Germany; ${ }^{20}$ Pioneer Valley Life Sciences Institute, Springfield, Massachusetts

\begin{abstract}
According to present estimations, the unfavorable combination of alleles with low penetrance but high prevalence in the population might account for the major part of hereditary breast cancer risk. Deleted in Malignant Brain Tumors 1 (DMBT1) has been proposed as a tumor suppressor for breast cancer and other cancer types. Genomewide mapping in mice further identified Dmbt 1 as a potential modulator of breast cancer risk. Here, we report the association of two frequent and linked single-nucleotide polymorphisms (SNPs) with increased breast cancer risk in women above the age of 60 years: DMBT1 c. $-93 \mathrm{C}>\mathrm{T}, \mathrm{rs} 2981745$, located in the DMBT1 promoter; and DMBT1 c.124A $>$ C, p.Thr42Pro, rs 11523871 (odds ratio $[O R]=1.66,95 \%$ confidence interval $[\mathrm{CI}]=1.21-2.29, \mathrm{P}=0.0017$; and $\mathrm{OR}=1.66$; $95 \% \mathrm{CI}=1.21-2.28, P=0.0016$, respectively), based on
\end{abstract}

\footnotetext{
†Sandrine Tchatchou and Angela Riedel contributed equally and should be considered as shared first authors.

Jan Mollenhauer and Barbara Burwinkel contributed equally and should be considered as shared last authors.

*Correspondence to: Sandrine Tchatchou, Helmholtz-University Group Molecular Epidemiology, German Cancer Research Center (DKFZ), Im Neuenheimer Feld 581, 69120 Heidelberg, Germany. E-mail: s.tchatchou@dkfz.de
}

1,195 BRCA1/2 mutation-negative German breast cancer families and 1,466 unrelated German controls. Promoter studies in breast cancer cells demonstrate that the riskincreasing DMBT1 -93T allele displays significantly decreased promoter activity compared to the DMBT1 -93C allele, resulting in a loss of promoter activity. The data suggest that DMBT1 polymorphisms in the $5^{\prime}$-region are associated with increased breast cancer risk. In accordance with previous results, these data link decreased DMBT1 levels to breast cancer risk. Hum Mutat 31:60-66, 2010. (c) 2009 Wiley-Liss, Inc.

KEY WORDS: DMBT1 gene; DMBT1 polymorphisms; breast cancer risk; risk factor

\section{Introduction}

Breast cancer is the most common cause of cancer-related death in women and, after lung cancer, the second most frequent cancer worldwide [Parkin et al., 2005]. Familial breast cancer accounts for approximately 5 to $10 \%$ of all breast cancers [Balmain et al., 2003; Nathanson et al., 2001; Wooster and Weber, 2003]. Germline mutations in BRCA1/2 occur in about 20 to $30 \%$ of all familial breast cancer cases and in 2 to $3 \%$ of all breast cancers [Balmain 
et al., 2003; Meindl, 2002; Wooster and Weber, 2003]. According to the polygenic model of inherited breast cancer, unfavorable combinations of genetic variants in low-penetrance susceptibility genes jointly contribute to the excess familial breast cancer risk. However, most of these susceptibility genes have not been discovered yet [Pharoah et al., 2002].

The gene Deleted in Malignant Brain Tumors 1 (DMBT1; GenBank NM_004406.2), located on human chromosome 10q26.13, encodes for a secreted high-molecular-weight glycoprotein of the scavenger receptor cysteine-rich (SRCR) superfamily [Mollenhauer et al., 1997]. The protein is expressed predominantly by epithelial cells. Lumenally secreted variants have been shown to play a role in the defense against bacterial and viral infections as well as in the regulation of inflammatory responses [Bikker et al., 2002; Hartshorn et al., 2003; Prakobphol et al., 2000; Rosenstiel et al., 2007]. In contrast, secretion of the protein to the extracellular matrix (ECM) may trigger processes of epithelial and/or stem cell differentiation [Takito and Al-Awqati, 2004; Vijayakumar et al., 1999].

Mutations within DMBT1 have been found only infrequently across various cancer types. The major mode of inactivation seems to be a downregulation at the transcriptional level, which, in some cancer types, is probably preceded by an upregulation during early tumorigenesis. In fact, various infectious, inflammatory, and carcinogenic stimuli lead to upregulation of DMBT1 in vitro and in vivo, suggesting its role in early protective responses [reviewed in Ligtenberg et al., 2007; Mollenhauer et al., 2007]. This may be particularly important in the mammary gland epithelium, where an early upregulation of Dmbtl protein has been observed after treatment of mice with the breast cancer-inducing carcinogen 7,12dimethybenz $(\alpha)$ anthracene (DMBA), while human breast cancer cells frequently display a downregulation compared to the flanking normal breast epithelium [Braidotti et al., 2004; Mollenhauer et al., 2004]. Recent genomewide mapping in $\operatorname{Trp} 53^{+/-}$mouse strains with differential breast cancer susceptibility depending on the genetic background have recovered a $25-\mathrm{Mb}$ region at mouse chromosome 7 designated as the Suppressor of mammary tumors 1 (SuprMam1) locus [Blackburn et al., 2007]. This locus also includes the mouse Dmbt1 gene. Expression profiling has identified Dmbt1 as 1 out of only 3 genes, which have displayed decreased expression levels in the normal mammary gland epithelium of the breast cancer susceptible vs. the resistant mice. Immunohistochemical studies further have suggested lower DMBT1 levels in the normal mammary gland epithelium of women with breast cancer compared to women without it [Blackburn et al., 2007].

Based on these data, we hypothesized that DMBT1 could represent a candidate for a novel breast cancer susceptibility gene. To test this hypothesis, we analyzed two single-nucleotide polymorphisms (SNPs), which are part of a larger haplotype block in the $5^{\prime}$-region of DMBT1, for their association with breast cancer risk in a large collection of index cases of 1,195 breast cancer families lacking BRCA1/2 mutations and 1,466 healthy control individuals.

\section{Materials and Methods}

\section{Study Population}

Genomic DNA was extracted from the peripheral lymphocytes. All breast cancer cases were classified into six categories: (A1) families with two or more cases of breast cancer including at least two cases with onset under the age of 50 years; (A2) families with at least one male breast cancer case; (B) families with one or more cases of breast and at least one ovarian cancer; (C) families with two or more cases of breast cancer including one case diagnosed before the age of 50 years; (D) families with two or more cases of breast cancer diagnosed after the age of 50 years; or (E) a single case of breast cancer with diagnosis before the age of 35 years. Thus, we accumulated familial cases and cases with early onset, which are more likely to be due to a genetic cause, in our study population. The breast cancer cases comprised only unrelated women that had been tested BRCA1/2 mutation-negative by applying the denaturing high-performance liquid chromatography (DHPLC) method on all exons, followed by direct sequencing of conspicuous exons. The samples, all of Caucasian origin, were collected during the years 1997 to 2005 by six centers of the German Consortium for Hereditary Breast and Ovarian Cancer (GC-HBOC: centers in Heidelberg, Würzburg, Cologne, Kiel, Düsseldorf, and Munich, see author affiliations for names). Index patients were first diagnosed with breast cancer and then referred to a family registry. All breast cancer patients gave an informed consent. The control population included healthy and unrelated female blood donors collected by the Institute of Transfusion Medicine and Immunology (Mannheim, Germany), sharing the ethnic background and sex with the breast cancer patients. The age distribution in the controls and cases was nearly identical (controls: mean age 45.6 years, median age 46 years; cases: mean age 45.1 years, median age 45 years). According to the German guidelines for blood donation, all blood donors were examined by a standard questionnaire and gave their informed consent. They were randomly selected during the years 2004 to 2007 for this study and no further inclusion criteria were applied during recruitment. The study was approved by the Ethics Committee of the University of Heidelberg (Heidelberg, Germany).

Choosing blood donator controls might have resulted in a selection bias. However, the selection factors are unlikely to be related to the SNPs of interest. Furthermore, established susceptibility loci have shown the expected associations/odds ratios (ORs) in the GCHBOC study population [Ahmed et al., 2009; Dunning et al., 2009; Frank et al., 2005; Milne et al., 2009; Shephard et al., 2009].

\section{Genotyping}

Genotyping analyses were performed on whole-genome-amplified (WGA) DNA of BRCA1/2 mutation-negative index patients from 1,195 German breast cancer families and 1,466 unrelated German controls. The whole genome amplification (WGA) of original genomic DNA was performed with the GenomiPhi DNA amplification kit (GE Healthcare Life Sciences, Piscataway, NJ) according to Wong et al. [2004] and the F29 DNA polymerase as described by Paez et al. [2004], respectively.

The polymorphisms DMBT1 c. $-93 \mathrm{C}>\mathrm{T}$; rs2981745 and DMBT1 c.124A>C, p.Thr42Pro; rs11523871 were investigated using TaqMan allelic discrimination. Primer and TaqMan MGB probes were purchased from Applied Biosystems (Foster City, CA): DMBT1 $1^{\mathrm{c}-93 \mathrm{C}>\mathrm{T}}$ : forward $5^{\prime}$-TTAGCAAAAGCCCTCACTTCCTT-3', reverse 5'-GGTGTGTCCTCTAGGGTGGTA-3'; TaqMan probes: forward 5'-CAGCAGCAGAAATA-3'-VIC, reverse $5^{\prime}$-CAGCAGTAGAAATA-3'-FAM; DMBT1 $1^{\text {c.124A }>\text { C }}$ : forward $5^{\prime}-$ CCATCAATGAGCTCTTCCTTTTCCA- $3^{\prime}$, reverse 5'-TCCCCCATAATAGACCTTACCTTCTG-3'; TaqMan probes: forward 5'-CCCTTGGATACAACTGT-3'-VIC, reverse 5'-CCTTGGATCCAACTGT-3'-FAM. Five nanograms of genomic DNA were used per assay. PCR was carried out at $50^{\circ} \mathrm{C}$ for 2 minutes; $95^{\circ} \mathrm{C}$ for 10 minutes; and 40 to 45 times at $92^{\circ} \mathrm{C}$ for 15 seconds and $60^{\circ} \mathrm{C}$ for 60 seconds. Samples were analyzed with the ABI Prism $7900 \mathrm{HT}$ detection system using SDS 1.2 software (Applied 
Biosystems). The polymorphisms were named relative to the reference sequence NM_004406.2 with nucleotide positions given for the cDNA, numbered with +1 corresponding to $\mathrm{A}$ of the start codon, ATG, in accordance with the recommendations of the Nomenclature Working Group [Antonarakis, 1998] (www.hgvs.org/mutnomen).

\section{Statistical Analysis}

Hardy-Weinberg equilibrium (HWE) test was undertaken using the chi-square "goodness-of-fit" test. Genotype-specific ORs, 95\% confidence intervals (CIs), and $P$-values were computed by unconditional logistic regression using a tool offered by the Institute of Human Genetics, Technical University Munich, Munich, Germany (http://ihg.gsf.de/cgi-bin/hw/hwal.pl). P-values were calculated using two-sided chi-square test. Given our sample size, we calculated a power of $80 \%(\alpha=0.05)$ to detect an OR of 1.25. Given our sample size, we had a power of $80 \%(\alpha=0.05)$ to detect an OR of 1.25 for both SNPs using the power and sample size calculation software PS version 2.1.31 (www.mc.vanderbilt. edu/prevmed/ps/index.htm), not considering the inclusion of familial cases. The power of an association study based on familial cases is about two times higher compared to a study of unselected cases [Antoniou and Easton, 2003]. Pairwise linkage disequilibrium (LD) was calculated between the investigated SNPs among the control population using $\left|\mathrm{D}^{\prime}\right|$ and $\mathrm{r}^{2}$ based on the Haploview program by Mark Daly [Barrett et al., 2005] (www.broad.mit.edu/ mpg/haploview/documentation.php) and the HapMap project (http://hapmart.hapmap.org/BioMart/martview/JIUfVsn0GF.mart). The LD between the SNPs was evaluated with the Haploview software [Barrett et al., 2005].

\section{Cell Lines and DMBT1 Expression Analyses}

Cell lines MCF7, T47D, MDA-MB-231, MCF10A, MCF12A, and BT549 were obtained from the American Type Culture Collection (ATCC, Manassas, VA). T47D and BT549 cells were cultivated in RPMI 1640 medium with $1 \mu \mathrm{g} / \mathrm{ml}$ insulin; MCF10A and MCF12A cells were cultivated in Dulbecco's modified Eagle's medium (DMEM) F12 with $10 \mu \mathrm{g} / \mathrm{ml}$ insulin, $0.5 \mu \mathrm{g} / \mathrm{ml}$ hydrocortisone, and $20 \mathrm{ng} / \mathrm{ml}$ human epidermal growth factor (hEGF); MCF7 cells in DMEM with $10 \mu \mathrm{g} / \mathrm{ml}$ insulin; and MDA-MB-231 cells in DMEM. All cell lines were cultured with $10 \%$ fetal calf serum (FCS) (except for MCF10A and MCF12A with 5\% FCS), $2 \mathrm{mM}$ L-glutamine, $100 \mathrm{U} / \mathrm{ml}$ penicillin, and $100 \mu \mathrm{g} / \mathrm{ml}$ streptomycin, at $37^{\circ} \mathrm{C}$ in a humidified, $5 \% \mathrm{CO}_{2}$ environment. Cells grown to $80 \%$ confluency were used for RNA extraction. Total RNA was isolated using the RNeasy kit from Qiagen (Hilden, Germany), according to the manufacturer's protocol. The RNA (500 ng total RNA) was then reversely transcribed into cDNA using oligo-dT priming. For quantitative reverse transcription PCR (qRT-PCR) we used $10 \mathrm{ng}$ cDNA and a TaqMan assay ondemand (Hs01069306_m1) for the DMBT1 gene (Applied Biosystems) according to the supplier's instructions. All TaqMan reactions were done in triplicate and signal detection was performed by a 7300 Real-Time PCR system (Applied Biosystems). The cycle thresholds $\left(C_{t}\right)$ were normalized against the $C_{t}$ values obtained for the human housekeeping genes $\beta$-actin and $G A P D H$. The $\Delta \Delta \mathrm{C}_{\mathrm{t}}$ value was calculated based on the $\Delta \mathrm{C}_{\mathrm{t}}$ values of the control. The expression level was than calculated as $\mathrm{X}_{\mathrm{L}}$ (expression level) $=2-\Delta \Delta \mathrm{C}_{\mathrm{t}}$. Analyses were made by the SDS v1.2 program and the RT-PCR program Biogazelle (free download at www.biogazelle.com).

\section{Analysis of Promoter Activities}

A 1,029-bp product comprising the activator region of the DMBT1 promoter [Lualdi et al., 2000] was amplified by PCR from genomic DNA of a donor heterozygous for the DMBT1 c.-93C > T SNP using the primers DMBT1/1278 (5'-GCG AGC TCA GCC TCT CAG CTGAGA AGC AG- $\left.3^{\prime}\right)$ and DMBT1/1241 (5'-CTG TGG AGA TCC CCATGG TGC TGG GTT CTT C-3'). A 446-bp SacI/NcoI (5'-part; Fig. 1A) restriction fragment was inserted into the $\mathrm{SacI} / \mathrm{NcoI}$-digested pGL3B vector. Subsequently, the 562-bp NcoI ( $3^{\prime}$-part) restriction fragment containing either the DMBT1 $-93 \mathrm{C}$ or the DMBT1 $-93 \mathrm{~T}$ variant was cloned into the NcoI-digested pGL3B vector already containing the 5 '-part. Finally, we excised the 683-bp NdeI/BsrGI fragment from the construct with the DMBT1-93T allele and inserted it in the NdeI/BsrGI digested vector with the DMBT1 -93C allele. This yielded constructs with the firefly luciferase reporter gene under control of the activator region of the DMBT1 promoter, which were identical except for the DMBT1 c. $-93 \mathrm{C}>\mathrm{T}$. Of each plasmid or of the empty pGL3B vector (control without promoter) $480 \mathrm{ng}$ were transiently cotransfected with $20 \mathrm{ng}$ of Renilla luciferase-encoding vector into MDA-MB-231 breast cancer cells $\left(1 \times 10^{5}\right.$ cells in 24 -well format) using the GeneJammer transfection reagent (Stratagene, La Jolla, CA). We used the Dual-Luciferase Reporter Assay System (Promega, Madison, WI) and a LUMIstar Omega luminometer (BMG LABTECH, Offenburg, Germany) for detection of reporter and transfection control gene expression 30 hours posttransfection as recommended by the suppliers. We calculated firefly:Renilla luciferase activity to adjust for transfection efficacy. The values were normalized against background activity of empty vector controls. Two independent experiments were performed in triplicate transfections, and data were compared by the two-tailed Student's $t$-test.

\section{Results}

We performed a case-control study analyzing BRCA1/2 mutationnegative female index patients from 1,195 breast cancer families and 1,466 female unrelated German controls. Previous studies indicated that decreased DMBT1 mRNA and/or protein expression levels in the mouse and human mammary gland epithelium could potentially be associated with breast cancer susceptibility [Blackburn et al., 2007]. We thus selected for initial analyses two SNPs in the $5^{\prime}$-region of the DMBT1 gene, which are part of a larger haplotype block. This comprised a C/T polymorphism at position $-93 \mathrm{bp}$ in relation to the DMBT1 start codon (rs2981745; DMBT1 c. $-93 \mathrm{C}>\mathrm{T}$ ) and a second closely linked SNP (rs11523871; DMBT1 c.124A > C, p.Thr42Pro; $\left.\mathrm{r}^{2}=0.93, \mathrm{D}=0.98\right)$. DMBT1 c. $-93 \mathrm{C}>\mathrm{T}$ is located between two putative alternative transcription initiation sites [Mollenhauer et al., 1997], while the coding SNP is located within a domain of unknown function subsequent to the putative signal peptide and resulted in a nonconservative amino acid exchange (p.Thr42Pro), which was predicted to have possible functional consequences according to the in silico prediction programs SIFT (http://blocks.fhcrc.org/sift) and PolyPhen (http://coot.embl.de/PolyPhen).

Genotype distribution in cases and controls were consistent with the HWE for both SNPs. As quality control 5\% of the samples for each study were randomly selected and subjected to repeated analysis, yielding a concordance rate of $100 \%$. Genotyping call rates for all studies were higher than $98 \%$.

Logistic regression analyses of DMBT1 c. $-93 \mathrm{C}>\mathrm{T}$; rs 2981745 revealed a significant association of the homozygous $-93 \mathrm{~T}$ genotype with familial breast cancer $(\mathrm{OR}=1.37,95 \% \mathrm{CI}=$ 1.04-1.80, $P=0.022$; Table 1). Similarly, homozygous carriers of the C allele of DMBT1 124C (42Pro) were found significantly 


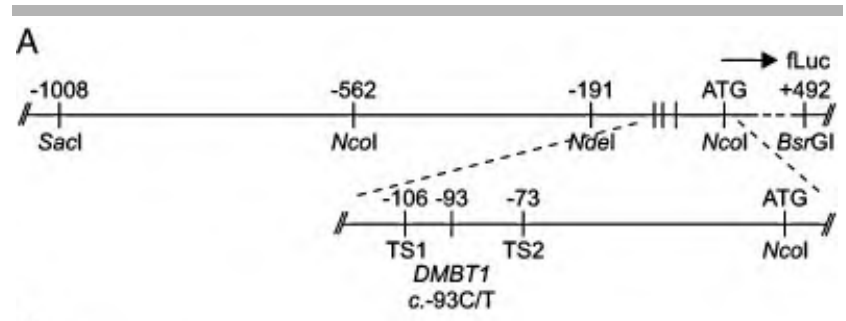

B

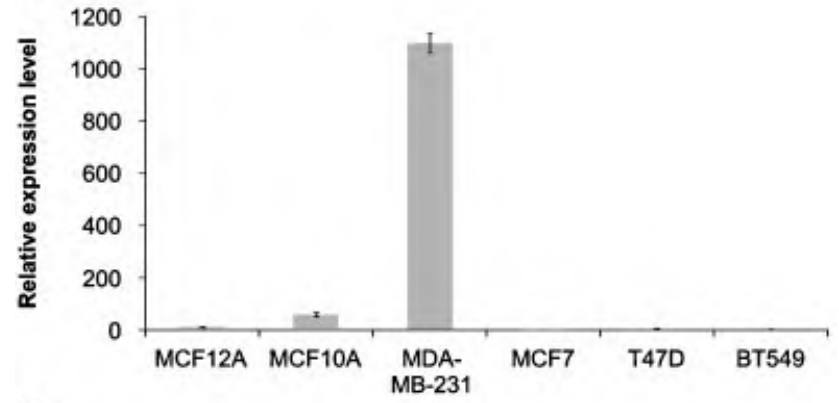

C

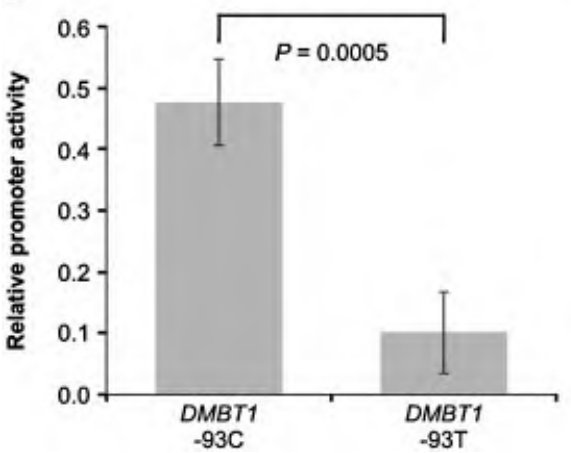

Figure 1. Comparison of the promoter activities of the DMBT1 c. $-93 \mathrm{C}>\mathrm{T}$ variants. A: (Top line) schematic presentation of the $1 \mathrm{~kb}$ promoter region with relevant recognition sites for restriction enzymes. According to previous data, this region contains elements that activate DMBT1 transcription [Lualdi et al., 2000; Rosenstiel et al., 2007]. (Bottom line) magnification of the region containing the $D M B T 1$ c. $-93 \mathrm{C}>\mathrm{T}$. The SNP locates between two presumable alternative transcription initiation sites (TS1 and TS2), located at positions -106 and $-73 \mathrm{bp}$ in relation to the ATG start codon [Mollenhauer et al., 1997]. B: Determination of relative DMBT1 expression levels in normal breast and breast cancer cell lines by qRT-PCR. The values were referred to MCF7 cells (set as 1). The breast cancer cell line MDAMB-231 displayed highest expression levels. According to the $C_{t}$ value of 25 for $D M B T 1$ (and a $\Delta C_{t}$ value of 3.7 compared to $\beta$-actin), it represented the only cell line with substantial expression levels. C: Relative reporter gene (firefly luciferase) activity in MDA-MB-231 cells of the $1 \mathrm{~kb}$ promoter fragment with either the DMBT1-93T or the $D M B T 1-93 C$ polymorphism. The variant with the DMBT1-93C polymorphism displays significantly higher activity compared to the one with the DMBT1 -93T polymorphism $(P=0.0005$ according to the two-tailed Student's $t$-test). Error bars represent standard error of the mean (SEM).

more frequent among breast cancer cases than among controls $(\mathrm{OR}=1.34, \quad 95 \% \quad \mathrm{CI}=1.02-1.75, \quad P=0.035 ;$ Table 1$)$. Age adjustment did not have appreciable effects on the respective ORs $(\mathrm{OR}=1.35$ for $D M B T 1$ c. $-93 \mathrm{C}>\mathrm{T}$ and $\mathrm{OR}=1.31$ for DMBT1 c.124A $>$ C, comparing rare homozygous genotype carriers vs. frequent homozygous genotypes). Both SNPs occurred with considerable frequencies in the control group ( 0.288 for DMBT1 -93T allele and 0.298 for DMBT1 124C allele).

To analyze whether the breast cancer risk associated with these polymorphisms potentially varied in different age groups, we divided the breast cancer cases and controls into five age groups: $\leq 30$ years, $>30$ to $\leq 40$ years, $>40$ to $\leq 50$ years, $>50$ to $\leq 60$ years, and $>60$ years; and calculated the OR between cases and controls of the respective age group. Interestingly, only the age group including breast cancer cases and controls $>60$ years of age showed a significant association of the $-93 \mathrm{~T}$ allele with an increased breast cancer risk $(\mathrm{OR}=1.66,95 \% \mathrm{CI}=1.21-2.29$, $P=0.0017$; Table 1). The risk effect was stronger for homozygous -93T variant allele carriers $(\mathrm{OR}=3.54,95 \% \mathrm{CI}=1.71-7.34$, $P=0.00039$; Table 1). In addition, the $\mathrm{C}$ allele of the DMBT1 124C (42Pro) was found significantly more frequently in cases than in controls in the $\geq 60$ age group $(\mathrm{OR}=1.66,95 \%$ $\mathrm{CI}=1.21-2.28, P=0.0016$; Table 1). Similar to the finding for the $-93 \mathrm{~T}$ allele, the risk was increased in homozygous carriers of the $124 \mathrm{C}$ allele $(\mathrm{OR}=3.23,95 \% \mathrm{CI}=1.55-6.72, \quad P=0.0011$; Table 1). The $\chi^{2}$-test for trend showed an allele dose-dependent association of the respective minor allele with increased familial breast cancer for both the DMBT1 c. $-93 \mathrm{C}>\mathrm{T}$; rs2981745 and the DMBT1 c.124A >C, p.Thr42Pro; rs11523871, respectively $\left(\mathrm{P}_{\text {trend }}=0.00157\right.$ and $\mathrm{P}_{\text {trend }}=0.00129$; Table 1$)$.

The status of the breast tumors for the estrogen receptor (ER) and the progesterone receptor (PR) was available for a subset of the cases (305 cases ER+/PR+ and 308 cases ER-/PR-). Stratification according to this parameter did not recover statistical significant differences in odds ratios between the hormone receptor positive and negative status (data not shown).

The two SNPs are part of a larger haplotype block, containing at least two further exonic SNPs, located further three-primed in codon 52 and codon 54. Furthermore, within the first $1 \mathrm{~kb}$ of the $D M B T 1$ promoter immediately preceding the start codon and previously shown to harbor activating elements [Lualdi et al., 2000; Rosenstiel et al., 2007], there is - except for the DMBT1 c. $-93 \mathrm{C}>\mathrm{T}$ $\mathrm{SNP}$ - another eight SNPs, a dinucleotide and tetranucleotide insertion/deletion polymorphism (not shown). The coding SNPs locate in an amino acid motif of so far unknown function and previous studies indicated that lower DMBT1 expression levels could be associated with increased risk for breast cancer in mice and humans [Blackburn et al., 2007]. Of the various SNPs in the DMBT1 promoter, the DMBT1 c. $-93 \mathrm{C}>\mathrm{T}$ SNP was of particular interest, because it represented the only alteration within the first $270 \mathrm{bp}$ preceding the start codon and further located between two putative transcription initiation sites (Fig. 1A) [Mollenhauer et al., 1997]. We thus cloned the $1 \mathrm{~kb}$ promoter fragment in front of a firefly luciferase reporter gene with either a $\mathrm{C}$ or a $\mathrm{T}$ at position -93 bp (Fig. 1A). Quantitative RT-PCR analyses suggested that MDA-MB-231 breast cancer cells display appreciable DMBT1 mRNA expression levels (Fig. 1B), which were thus selected for studying promoter activities. The data suggested that the breast cancer associated DMBT1 $-93 \mathrm{~T}$ variant displayed no significant promoter activity compared to the promoter-deficient control vector $(10 \% \pm 7 \% ; P=0.14$ according to the Student's two-tailed $t$-test; not shown), while the DMBT1 $-93 \mathrm{C}$ variant displayed significantly higher promoter activity $\left(P=8 \times 10^{-8}\right.$ compared to the empty vector, and $P=0.0005$ compared to the DMBT1 $-93 \mathrm{~T}$ variant; Fig. 1C). These data suggested that the DMBT1 $-93 \mathrm{~T}$ variant, which is associated with an increased risk for breast cancer, displays a strongly reduced promoter activity in vitro.

\section{Discussion}

Low penetrance susceptibility genes are considered to contribute a major portion of hereditary breast cancer risk due to the common occurrence of risk variants within the population [Pharoah et al., 
Table 1. Genotype Frequencies of DMBT1 Polymorphisms $-93 \mathrm{C}>\mathrm{T}$ and Thr42Pro in All and in Different Age Groups in the German Study Population*

\begin{tabular}{|c|c|c|c|c|c|c|}
\hline SNP & Genotypes & Cases & Controls & OR & $95 \% \mathrm{CI}$ & $P$ \\
\hline \multicolumn{7}{|c|}{ All cases and controls } \\
\hline & CC (\%) & $585(49.1)$ & $740(50.5)$ & 1 & & \\
\hline & CT (\%) & $481(40.3)$ & $609(41.5)$ & 0.99 & $0.85-1.17$ & 0.991 \\
\hline & $\mathrm{TT}(\%)$ & $127(10.6)$ & $117(8.0)$ & 1.37 & $1.04-1.80$ & 0.022 \\
\hline \multicolumn{4}{|c|}{$[\mathrm{T}] \leftrightarrow[\mathrm{C}]$} & 1.10 & $0.98-1.24$ & 0.103 \\
\hline \multicolumn{7}{|c|}{ Cases and controls $\leq 30$ years } \\
\hline & CC (\%) & $40(51.3)$ & $143(45.8)$ & 1 & & \\
\hline & CT (\%) & $31(39.7)$ & $143(45.8)$ & 0.77 & $0.46-1.21$ & 0.339 \\
\hline & TT (\%) & $7(9.0)$ & $26(8.4)$ & 0.96 & $0.39-2.38$ & 0.934 \\
\hline \multicolumn{6}{|c|}{$[\mathrm{T}] \leftrightarrow[\mathrm{C}] \quad 0.89 \quad 0.61-1.31 \quad 0.561$} & 0.561 \\
\hline \multicolumn{7}{|c|}{ Cases and controls $>30$ to $\leq 40$ years } \\
\hline & $\mathrm{CC}(\%)$ & $126(46.8)$ & $105(45.8)$ & 1 & & \\
\hline$-93 C>T$ & $\mathrm{CT}(\%)$ & $116(43.1)$ & $106(46.3)$ & 0.91 & $0.63-1.32$ & 0.625 \\
\hline \multirow[t]{2}{*}{ rs2981745 } & $\mathrm{TT}(\%)$ & $27(10.1)$ & $18(7.9)$ & 1.25 & $0.65-2.39$ & 0.501 \\
\hline & & {$[\mathrm{T}]$} & $\rightarrow[\mathrm{C}]$ & 1.03 & $0.78-1.34$ & 0.840 \\
\hline \multicolumn{7}{|c|}{0 years } \\
\hline & $\mathrm{CC}(\%)$ & $83(43.9)$ & $244(51.0)$ & 1 & & \\
\hline & CT $(\%)$ & $88(46.6)$ & $183(38.3)$ & 0.71 & $0.49-1.01$ & 0.056 \\
\hline & TT (\%) & $18(9.5)$ & $51(10.7)$ & 0.96 & $0.53-1.74$ & 0.903 \\
\hline \multicolumn{4}{|c|}{$[\mathrm{T}] \leftrightarrow[\mathrm{C}]$} & 0.87 & $0.67-1.12$ & 0.285 \\
\hline \multicolumn{7}{|c|}{ Cases and controls $>50$ to $\leq 60$ years } \\
\hline & $\mathrm{CC}(\%)$ & $112(56.0)$ & $223(57.2)$ & 1 & & \\
\hline & CT $(\%)$ & $88(44.0)$ & $131(33.6)$ & 1.34 & $0.94-1.90$ & 0.106 \\
\hline & TT (\%) & $20(10.0)$ & $36(9.2)$ & 1.11 & $0.61-1.99$ & 0.738 \\
\hline \multicolumn{4}{|c|}{$[\mathrm{T}] \leftrightarrow[\mathrm{C}]$} & 1.17 & $0.89-1.51$ & 0.247 \\
\hline \multicolumn{7}{|c|}{ Cases and controls $>60$ years } \\
\hline & $\mathrm{CC}(\%)$ & $47(41.6)$ & $186(53.8)$ & 1 & & \\
\hline & CT $(\%)$ & $49(43.4)$ & $141(40.7)$ & 1.37 & $0.87-2.17$ & 0.170 \\
\hline & TT (\%) & $17(15.0)$ & $19(5.5)$ & 3.54 & $1.71-7.34$ & 0.00039 \\
\hline \multicolumn{4}{|c|}{$[\mathrm{T}] \leftrightarrow[\mathrm{C}]$} & 1.66 & $1.21-2.29$ & 0.0017 \\
\hline & & & & & $P_{\text {trend }}=0$ & .00157 \\
\hline \multicolumn{7}{|c|}{ All cases and controls } \\
\hline & $\mathrm{AA}(\%)$ & $569(47.6)$ & $714(48.7)$ & 1 & & \\
\hline & $\mathrm{AC}(\%)$ & $497(41.6)$ & $631(43.1)$ & 0.99 & $0.84-1.16$ & 0.886 \\
\hline & CC (\%) & $129(10.8)$ & $121(8.2)$ & 1.34 & $1.02-1.75$ & 0.035 \\
\hline \multicolumn{4}{|c|}{$[\mathrm{C}] \leftrightarrow[\mathrm{A}]$} & 1.08 & $0.97-1.22$ & 0.153 \\
\hline & Case & $\mathrm{s}$ and contro & ls $\leq 30$ year & & & \\
\hline & $\mathrm{AA}(\%)$ & $42(51.2)$ & $141(45.1)$ & 1 & & \\
\hline & $\mathrm{AC}(\%)$ & $33(40.2)$ & $145(46.3)$ & 0.76 & $0.46-1.27$ & 0.302 \\
\hline & CC (\%) & $7(8.6)$ & $27(8.6)$ & 0.87 & $0.35-2.14$ & 0.762 \\
\hline & & {$[\mathrm{C}] \leftarrow$} & $\rightarrow[\mathrm{A}]$ & 0.86 & $0.59-1.26$ & 0.441 \\
\hline & Cases an & $\mathrm{d}$ controls $>$ & 30 to $\leq 40$ & vears & & \\
\hline Thr42Pro & $\mathrm{AA}(\%)$ & $121(45.3)$ & $99(43.8)$ & 1 & & \\
\hline $124 \mathrm{~A}>\mathrm{C}^{\mathrm{a}}$ & $\mathrm{AC}(\%)$ & $117(43.8)$ & $107(47.3)$ & 0.89 & $0.62-1.30$ & 0.559 \\
\hline rs11523871 & CC (\%) & $29(10.9)$ & $20(8.9)$ & 1.19 & $0.63-2.22$ & 0.594 \\
\hline & & {$[\mathrm{C}]$} & $\rightarrow[\mathrm{A}]$ & 1.01 & $0.77-1.32$ & 0.934 \\
\hline & Cases an & $\mathrm{d}$ controls $>$ & 40 to $\leq 50$ & vears & & \\
\hline & $\mathrm{AA}(\%)$ & $240(49.9)$ & $81(42.9)$ & 1 & & \\
\hline & $\mathrm{AC}(\%)$ & $190(39.5)$ & $91(48.1)$ & 0.70 & $0.49-1.00$ & 0.052 \\
\hline & CC (\%) & $51(10.6)$ & $17(9.0)$ & 1.01 & $0.55-1.85$ & 0.968 \\
\hline & & {$[\mathrm{C}]$} & $\rightarrow[\mathrm{A}]$ & 0.88 & $0.68-1.14$ & 0.334 \\
\hline & Cases an & $\mathrm{d}$ controls $>$ & 50 to $\leq 60$ & vears & & \\
\hline & $\mathrm{AA}(\%)$ & $110(50.5)$ & $215(54.9)$ & 1 & & \\
\hline & $\mathrm{AC}(\%)$ & 87 (39.9) & $141(35.9)$ & 1.21 & $0.85-1.72$ & 0.297 \\
\hline & CC (\%) & $21(9.6)$ & $36(9.2)$ & 1.14 & $0.63-2.05$ & 0.660 \\
\hline & & {$[\mathrm{C}]$} & $\rightarrow[\mathrm{A}]$ & 1.13 & $0.87-1.46$ & 0.367 \\
\hline & Case & s and contro & ls $>60$ year & & & \\
\hline & $\mathrm{AA}(\%)$ & $42(37.5)$ & $178(51.4)$ & 1 & & \\
\hline & $\mathrm{AC}(\%)$ & $54(48.2)$ & $147(42.5)$ & 1.56 & $0.98-2.46$ & 0.057 \\
\hline & CC (\%) & $16(14.3)$ & $21(6.1)$ & 3.23 & $1.55-6.72$ & 0.0011 \\
\hline & & {$[\mathrm{C}] \leftarrow$} & $\rightarrow[\mathrm{A}]$ & 1.66 & $1.21-2.28$ & 0.0016 \\
\hline & & & & & $P_{\text {trend }}=$ & 0.00129 \\
\hline
\end{tabular}

*Including ORs with 95\% CIs, and $P$-values. Bold indicates significant values. ${ }^{\text {a }}$ Relative to ATG according to NM_004406.2.

2002]. Initial studies of breast carcinogenesis in human tumors and mouse models pointed to a role for DMBT1 as tumor suppressor and/or susceptibility gene for breast cancer [Blackburn et al., 2007; Braidotti et al., 2004; Mollenhauer et al., 2004].
Our genetic studies assessed the relevance to familial breast cancer of the two linked DMBT1 variants DMBT1 c. $-93 \mathrm{C}>\mathrm{T}$; rs2981745 and DMBT1 c.124A >C, p.Thr42Pro; rs11523871. A recent study reported that SNPs located close to the estrogenand progesterone-responsive elements (EREs and PREs) within the DMBT1 promoter are not associated with risk for sporadic breast cancer but may affect survival of breast cancer patients [Lei et al., 2007]. Using a Cox regression analysis to evaluate the combined effect of genotype grade, PR and ER status on survival, the authors observed a two-fold increased risk for the rare AA genotype when compared with that for $\mathrm{CC}(\mathrm{RR}=2.0,95 \% \mathrm{CI}=1.0-5.0, P=0.04)$, suggesting a worse survival for the AA genotype carriers than the CC genotype carriers, independent of grade and hormone receptor status [Lei et al., 2007]. Because HapMap data are not available for these SNPs, we could not perform an analysis to determine their linkage disequilibrium to the SNPs analyzed in the present study.

We found that homozygous carriers of the DMBT1 -93T and DMBT1 124C (42Pro) variant were significantly overrepresented in the breast cancer group. The risk effect was stronger in the group including breast cancer cases and controls $>60$ years old. The strength of the present study is the large sample size of familial index cases resulting in high statistical power. Furthermore, exclusively BRCA1/2 mutation negative familial breast cancer cases were included in the study to avoid the effects deriving from mutations in these high-penetrance susceptibility genes.

We wanted to compare our data with results of the Cancer Genetic Markers of Susceptibility (CGEMs) study database, an National Cancer Institute (NCI) enterprise initiative to conduct Whole Genome Association Studies (WGAS) to identify genes giving rise to prostate and breast cancer risk by analyzing about 1,140 breast cancer cases and 1,140 controls via Illumina HumanHap550 assays (U.S. female nurses; https://caintegrator. nci.nih.gov/cgems). However, neither both SNPs themselves, nor SNPs with $r^{2} \geq 0.80$ have been analyzed in CGEMs.

Previous data indicated that decreased DMBT1 mRNA and protein levels in the mouse and human mammary gland epithelium, respectively, could be associated with increased breast cancer risk [Blackburn et al., 2007]. In the present study, we therefore focused on the $5^{\prime}$-region of the gene, which presumably contains critical elements for the regulation of DMBT1 mRNA expression [Lualdi et al., 2000; Rosenstiel et al., 2007] and processing of the protein, e.g., the signal peptide [Mollenhauer et al., 1997]. The promoter polymorphism is located $146 \mathrm{bp}$ downstream from 1 of the 6 progesterone receptor (PR) binding sites occurring in the $5^{\prime}$ flanking region of DMBT1 [Ace and Okulicz, 2005] and 21 bp upstream of the TATA-Box (www.cbil. upenn.edu/tess). Further, it locates between two putative alternative transcription initiation sites (Fig. 1A) [Mollenhauer et al., 1997] and represents the only polymorphism in the $270 \mathrm{bp}$ preceding the ATG start codon. According to our promoter studies in vitro, the single substitution of the $\mathrm{C}$ for a $\mathrm{T}$ at position -93 results in virtually abolishing the promoter activity of the $1 \mathrm{~kb}$ activatory region of the DMBT1 promoter. This is in good agreement with earlier findings suggesting that lowered DMBT1 expression levels confer susceptibility to breast carcinogenesis [Blackburn et al., 2007], and with the present observation that the $D M B T 1$-93T variant increases breast cancer risk.

The DMBT1 c. $-93 \mathrm{C}>\mathrm{T}$ variant is in very high $\mathrm{LD}(\mathrm{D}=0.98$, $\left.\mathrm{r}^{2}=0.93\right)$ with $D M B T 1$ c. $124 \mathrm{~A}>\mathrm{C}$, p.Thr42Pro, resulting in a nonsynonymous threonine to proline exchange. Furthermore, the first $1 \mathrm{~kb}$ of the DMBT1 promoter contains another eight SNPs and two insertion/deletion polymorphisms, predicting that the DMBT1 -93T variant occurs in cis with a number of further 
genetic variations. Thus, it should be taken into consideration that other polymorphisms might exist that affect the DMBT1 promoter activity, including elements located outside the $1 \mathrm{~kb}$ segment analyzed in the present study that might modulate mRNA expression, translation or posttranslational processing. Hence, systematic studies of the single and combined effects of these variations would be necessary. Furthermore, it has to be considered that larger deletion/insertion polymorphisms were detected in the DMBT1 gene. These substantially alter the number of SRCR domains within the protein, which are thought to exert critical functions in ligand interactions [Bikker et al., 2002; Mollenhauer et al., 2002; Renner et al., 2007]. The corresponding exons reside within a repetitive region located $3^{\prime}$ to the SNPs analyzed in the present study, and may consist of up to 13 repeats sharing high homology in exon and intron sequences [Mollenhauer et al., 1997, 1999, 2002]. Probably due to high recombination rates, these deletion/insertion polymorphisms are in poor LD to the SNPs in the flanking regions [Mollenhauer et al., 1999; Renner et al., 2007]. Accordingly, the association observed for the SNPs in the present study could also indicate an involvement of the deletion/insertion polymorphisms.

Taken together, we identified DMBT1 as a candidate for a novel low-penetrance breast cancer susceptibility gene, in particular for the age group of women of $>60$ years. The precise mechanistic background remains to be determined, but the fact that the breast cancer risk-increasing DMBT1 -93T promoter polymorphism significantly decreases the activity of the promoter in vitro is in good agreement with earlier data suggesting that low DMBT1 levels might be associated with an increased breast cancer risk in mice and humans.

\section{Acknowledgments}

This work was supported by the Helmholtz Society, the Ingeborg og Leo Dannins Fondens Legat 2009, the DKFZ, the Dietmar-Hopp Foundation, and the EU (LSHC-CT-2004-5034). The German breast cancer samples were collected the German Consortium for Hereditary Breast Cancer, funded by the Deutsche Krebshilfe (107054). We are grateful to Rongxi Yang for critical comments on the article.

\section{References}

Ace CI, Okulicz WC. 2005. The $5^{\prime}$ flanking region of the Rhesus monkey H3 (DMBT1) gene contains putative progesterone response elements. DNA Cell Biol 24:345-349.

Ahmed S, Thomas G, Ghoussaini M, Healey CS, Humphreys MK, Platte R, Morrison J, Maranian M, Pooley KA, Luben R, et al. 2009. Newly discovered breast cancer susceptibility loci on 3p24 and 17q23.2. Nat Genet 41:585-590.

Antonarakis SE. 1998. Recommendations for a nomenclature system for human gene mutations. Nomenclature Working Group. Hum Mutat 11:1-3.

Antoniou AC, Easton DF. 2003. Polygenic inheritance of breast cancer: implications for design of association studies. Genet Epidemiol 25:190-202.

Balmain A, Gray J, Ponder B. 2003. The genetics and genomics of cancer. Nat Genet 33(Suppl):238-244.

Barrett JC, Fry B, Maller J, Daly MJ. 2005. Haploview: analysis and visualization of LD and haplotype maps. Bioinformatics 21:263-265.

Bikker FJ, Ligtenberg AJ, Nazmi K, Veerman EC, van't Hof W, Bolscher JG, Poustka A, Nieuw Amerongen AV, Mollenhauer J. 2002. Identification of the bacteria-binding peptide domain on salivary agglutinin (gp-340/DMBT1), a member of the scavenger receptor cysteine-rich superfamily. J Biol Chem 277:32109-32115.

Blackburn AC, Hill LZ, Roberts AL, Wang J, Aud D, Jung J, Nikolcheva T, Allard J, Peltz G, Otis CN, Cao QJ, Ricketts RS, Naber SP, Mollenhauer J, Poustka A, Malamud D, Jerry DJ. 2007. Genetic mapping in mice identifies DMBT1 as a candidate modifier of mammary tumors and breast cancer risk. Am J Pathol 170:2030-2041.
Braidotti P, Nuciforo PG, Mollenhauer J, Poustka A, Pellegrini C, Moro A, Bulfamante G, Coggi G, Bosari S, Pietra GG. 2004. DMBT1 expression is down-regulated in breast cancer. BMC Cancer 4:46.

Dunning AM, Healey CS, Baynes C, Maia AT, Scollen S, Vega A, Rodríguez R, Barbosa-Morais NL, Ponder BA; SEARCH, Low YL, Bingham S; EPIC, Haiman CA, Le Marchand L, and many others. 2009. Association of ESR1 gene tagging SNPs with breast cancer risk. Hum Mol Genet 18:1131-1139.

Frank B, Bermejo JL, Hemminki K, Klaes R, Bugert P, Wappenschmidt B, Schmutzler RK, Burwinkel B. 2005. Re: Association of a common variant of the CASP8 gene with reduced risk of breast cancer. J Natl Cancer Inst 97:1012; author reply 1012-1013.

Hartshorn KL, White MR, Mogues T, Ligtenberg T, Crouch E, Holmskov U. 2003. Lung and salivary scavenger receptor glycoprotein-340 contribute to the host defense against influenza A viruses. Am J Physiol Lung Cell Mol Physiol 285: L1066-L1076.

Lei H, Hemminki K, Johansson R, Altieri A, Enquist K, Henriksson R, Lenner P, Forsti A. 2007. Single nucleotide polymorphisms in the DMBT1 promoter and the progression of breast cancer. Int J Cancer 120:447-449.

Ligtenberg AJ, Veerman EC, Nieuw Amerongen AV, Mollenhauer J. 2007. Salivary agglutinin/glycoprotein-340/DMBT1: a single molecule with variable composition and with different functions in infection, inflammation and cancer. Biol Chem 388:1275-1289.

Lualdi E, Chiariello E, Finocchiaro G. 2000. Identification of regulatory regions of the putative tumor suppressor gene DMBT1. Biochem Biophys Res Commun 270:673-675.

Meindl A. 2002. Comprehensive analysis of 989 patients with breast or ovarian cancer provides BRCA1 and BRCA2 mutation profiles and frequencies for the German population. Int J Cancer 97:472-480.

Milne RL, Benitez J, Nevanlinna H, Heikkinen T, Aittomaki K, Blomqvist C, Arias JI, Zamora MP, Burwinkel B, Bartram CR, Meindl A, Schmutzler RK, Cox A, Brock I, Elliott G, Reed MW, Southey MC, Smith L, Spurdle AB, and many others. 2009. Risk of estrogen receptor-positive and -negative breast cancer and singlenucleotide polymorphism 2q35-rs13387042. J Natl Cancer Inst 101:1012-1018.

Mollenhauer J, Wiemann S, Scheurlen W, Korn B, Hayashi Y, Wilgenbus KK, von Deimling A, Poustka A. 1997. DMBT1, a new member of the SRCR superfamily, on chromosome 10q25.3-26.1 is deleted in malignant brain tumours. Nat Genet 17:32-39.

Mollenhauer J, Holmskov U, Wiemann S, Krebs I, Herbertz S, Madsen J, Kioschis P, Coy JF, Poustka A. 1999. The genomic structure of the DMBT1 gene: evidence for a region with susceptibility to genomic instability. Oncogene 18:6233-6240.

Mollenhauer J, Muller H, Kollender G, Lyer S, Diedrichs L, Helmke B, Holmskov U, Ligtenberg T, Herbertz S, Krebs I, Madsen J, Bikker F, Schmitt L, Wiemann S, Scheurlen W, Otto HF, von Deimling A, Poustka A. 2002. The SRCR/SID region of DMBT1 defines a complex multi-allele system representing the major basis for its variability in cancer. Genes Chromosomes Cancer 35:242-255.

Mollenhauer J, Helmke B, Medina D, Bergmann G, Gassler N, Muller H, Lyer S, Diedrichs L, Renner M, Wittig R, Blaich S, Hamann U, Madsen J, Holmskov U, Bikker F, Ligtenberg A, Carlén A, Olsson J, Otto HF, O’Malley B, Poustka A. 2004. Carcinogen inducibility in vivo and down-regulation of DMBT1 during breast carcinogenesis. Genes Chromosomes Cancer 39:185-194.

Mollenhauer J, End C, Renner M, Lyer S, Poustka A. 2007. DMBT1 as an archetypal link between infection, inflammation, and cancer. Immunologia 26:193-209.

Nathanson KL, Wooster R, Weber BL. 2001. Breast cancer genetics: what we know and what we need. Nat Med 7:552-556.

Paez JG, Lin M, Beroukhim R, Lee JC, Zhao X, Richter DJ, Gabriel S, Herman P, Sasaki H, Altshuler D, Li C, Meyerson M, Sellers WR. 2004. Genome coverage and sequence fidelity of phi29 polymerase-based multiple strand displacement whole genome amplification. Nucleic Acids Res 32:e71.

Parkin DM, Bray F, Ferlay J, Pisani P. 2005. Global cancer statistics, 2002. CA Cancer J Clin 55:74-108.

Pharoah PD, Antoniou A, Bobrow M, Zimmern RL, Easton DF, Ponder BA. 2002. Polygenic susceptibility to breast cancer and implications for prevention. Nat Genet 31:33-36.

Prakobphol A, Xu F, Hoang VM, Larsson T, Bergstrom J, Johansson I, Frängsmyr L, Holmskov U, Leffler H, Nilsson C, Borén T, Wright JR, Strömberg N, Fisher SJ. 2000. Salivary agglutinin, which binds Streptococcus mutans and Helicobacter pylori, is the lung scavenger receptor cysteine-rich protein gp-340. J Biol Chem 275:39860-39866

Renner M, Bergmann G, Krebs I, End C, Lyer S, Hilberg F, Helmke B, Gassler N, Autschbach F, Bikker F, Strobel-Freidekind O, Gronert-Sum S, Benner A, Blaich S, Wittig R, Hudler M, Ligtenberg AJ, Madsen J, Holmskov U, Annese V, Latiano A, Schirmacher P, Amerongen AV, D'Amato M, Kioschis P, Hafner M, Poustka A, Mollenhauer J. 2007. DMBT1 confers mucosal protection in vivo and a deletion variant is associated with Crohn's disease. Gastroenterology 133:1499-1509. 
Rosenstiel P, Sina C, End C, Renner M, Lyer S, Till A, Hellmig S, Nikolaus S, Folsch UR, Helmke B, Autschbach F, Schirmacher P, Kioschis P, Hafner M, Poustka A, Mollenhauer J, Schreiber S. 2007. Regulation of DMBT1 via NOD2 and TLR4 in intestinal epithelial cells modulates bacterial recognition and invasion. J Immunol 178:8203-8211.

Shephard ND, Abo R, Rigas SH, Frank B, Lin WY, Brock IW, Shippen A, Balasubramanian SP, Reed MW, Bartram CR, Meindl A, Schmutzler RK, Engel C, Burwinkel B, Cannon-Albright LA, Allen-Brady K, Camp NJ, Cox A. 2009. A breast cancer risk haplotype in the caspase-8 gene. Cancer Res 69:2724-2728.
Takito J, Al-Awqati Q. 2004. Conversion of ES cells to columnar epithelia by hensin and to squamous epithelia by laminin. J Cell Biol 166:1093-1102.

Vijayakumar S, Takito J, Hikita C, Al-Awqati Q. 1999. Hensin remodels the apical cytoskeleton and induces columnarization of intercalated epithelial cells: processes that resemble terminal differentiation. J Cell Biol 144:1057-1067.

Wong KK, Tsang YT, Shen J, Cheng RS, Chang YM, Man TK, Lau CC. 2004. Allelic imbalance analysis by high-density single-nucleotide polymorphic allele (SNP) array with whole genome amplified DNA. Nucleic Acids Res 32:e69.

Wooster R, Weber BL. 2003. Breast and ovarian cancer. N Engl J Med 348:2339-2347. 